\title{
ELEMENTOS DA RATIO DECIDENDI: FATOS MATERIAIS, SOLUÇÃO JURÍDICA E MOTIVAÇÃO JUSTIFICATÓRIA
}

\section{Clívia Marcolongo Pereira Guzansky*}

RESUMO: Este trabalho analisa a ratio decidendi, propondo-se, a partir do método dedutivo, equacionar a necessidade de homogeneização conceitual e funcional desse componente decisório tão sensível à teoria dos precedentes. Discutem-se o problema conceitual, o seu desenvolvimento na doutrina estrangeira e a proposta nacional de menção ao elemento determinante - eleito pelo legislador ordinário - como integrante do conceito de ratio, e, finalmente, apresenta-se a norma de julgamento como a soma dos elementos fático materiais, solução jurídica e motivação justificatória, que se pretende demonstrar imprescindível à renovação do direito jurisdicional ao passo das evoluções sociais, pela garantia de participação no processo decisório.

PALAVRAS-CHAVE: ratio decidendi; obter dicta; precedente; norma decisória; direito jurisdicional

\section{RATIO DECIDENDI: MATERIAL FACTS, RULE OF THE CASE AND JUSTIFICATION-MOTIVATION}

ABSTRACT: This work exams the ratio decidendi, proposing, from the deductive method, to homogenize the concept and function of this decision component, so important to the theory of precedents. The conceptual problem, its development in foreign doctrine and the national proposal for the addition of the determining element - elected by the ordinary legislator - as part of the concept of ratio are discussed in this article. Finally, the ratio decidendi is presented as the sum of the material facts, the rule of the case and the justification-motivation. KEY-WORDS: ratio decidendi; obter dicta; precedent; rule of the case; jurisdictional law.

\section{INTRODUÇÃO}

A teoria dos precedentes busca garantir racionalidade aos sistemas de justiça, não obstante suas tradições jurídicas. Está assentada na premissa humana fundamental de que há justiça em tratar casos iguais de forma correspondente, de tal modo que nenhum sistema pode se declarar justo se não é capaz de fornecer aos jurisdicionados sequer a mais comezinha segurança de que a solução adjudicada aos conflitos interpessoais constitui o direito vigente para qualquer caso análogo, seja do rei ou do súdito.

\footnotetext{
* Mestranda em Direito Processual pelo Programa de pós-graduação stricto sensu em Direito Processual da Universidade Federal do Espírito Santo - UFES. Especialista em Direito Penal e Processual Penal pela Faculdade de Direito da Fundação Escola Superior do Ministério Público. Assessora Jurídica no Ministério Público no Estado do Espírito Santo. Lattes: http://lattes.cnpq.br/2442184690249812. E-mail: cliviamp@gmail.com
} 
Essa foi a pretensão do positivismo jurídico, o qual foi erigido sobre a visão utópica de que a lei geral e abstrata poderia antever todos os potenciais conflitos humanos em suas complexas relações, regulando-os de forma isonômica e eficiente, ao ponto de reduzir o exercício racional/cognitivo do julgador à singela aplicação da regra (premissa maior), ao caso (premissa menor).

No entanto, o tempo mostrou a grande falibilidade dessa teoria para a garantia de uma ordem jurídica com pretensão de ser justa, afinal, tanto as relações humanas são mais complexas do que o imaginário legislativo - não importa quão ativos sejam os representantes eleitos desse poder estatal, e, é bem sabido, no Brasil não se pode imputar aos parlamentares o desvio da inatividade, sendo o elevado número de leis, emendas legais e até emendas constitucionais uma evidência eloquente dessa assertiva -, como a lei é texto e, como tal, reclama interpretação.

Com isso, pelo menos duas distorções à pretensão positivista puderam ser observadas: de um lado, conflitos não contemplados por regras prévias vigentes, exigindo uma atividade "criativa" do julgador para a composição de conflitos; de outro, regras recebendo diferentes interpretações, sem que, num ou noutro caso, fossem estabelecidos mecanismos de controle para impedir que cada julgador desenvolvesse seu próprio catálogo legal.

A situação era ainda mais grave no caso brasileiro, já que o controle incidental de constitucionalidade habilitava cada julgador a ter sua própria constituição, numa incoerência sistêmica diagnosticada por Dinamarco como um paradoxo metodológico (1993, 49-45).

Esses problemas foram objeto de investigação da teoria da norma e da argumentação, resultando numa virada epistemológica que atribuiu uma nova forma de entender e compreender o processo decisório judicial.

Portanto, era mesmo questão de tempo que a busca por racionalidade e segurança ao sistema de justiça nacional abreviasse a dicotomia cultural que insistia na premissa de sistemas fechados e passasse a abrandar essas diferenças para acolher uma teoria de precedentes.

Mas por que essa teoria desperta tantas objeções? Se é pela tensão republicana da separação dos poderes, no Brasil, a implementação dessa vinculação ao precedente judicial foi introduzida por ato legislativo através do Código de Processo Civil de 2015; se é por 
tradicionalismo, não há razão em se manter tradições tão acentuadamente marcadas pela irracionalidade; se é pela desconfiança em relação aos juízes e tribunais, esse temor pode ser fruto de uma má-compreensão da teoria e a forma de sua aplicação e desenvolvimento.

Diante desse quadro, vê-se justificada a importância de se estudar os elementos que compõem uma decisão precedente. O recorte teórico é a ratio decidendi, tanto pela imprecisão doutrinaria acerca do seu conceito, com o que este artigo procura contribuir traçando uma linha evolutiva e justificatória dos elementos que foram sendo integrados a esse componente da decisão judicial, como pela observação de que a ausência de homogeneização e sistematização encerram o potencial de abreviar o debate público-jurídico sobre determinadas questões, o que tem a ver com um problema subjacente à adoção de um sistema de precedentes quando se há tantos embaraços de acesso recursal às Cortes Supremas, que é a possibilidade de engessamento do direito jurisprudencial, tão importante para a evolução da justiça por permitir a melhor adaptação do direito aos contínuos avanços sociais, mas tão ameaçado pelos mecanismos de contingenciamento numérico que dificultam a revisão do precedente pelo Órgão que o editou. Nesse ponto, este ensaio busca apresentar a motivação justificatória como um elemento da ratio e pondera que, se a decisão judicial é a síntese do debate jurídico desenvolvido para o caso, os fundamentos não levados ao exame do julgador do caso-precedente, mas que sejam robustos e capazes de, em tese, infirmar o resultado daquele julgamento, podem ser suscitados à nível de distinção no caso-presente e autorizar a superação da norma de julgamento, ainda que de forma parcial - porque circunscrita ao caso -, mas estável em relação ao julgador.

Com essa proposta em mente, a partir do método dedutivo, este ensaio busca equacionar a necessidade de homogeneização conceitual e funcional desse componente decisório tão sensível à teoria dos precedentes. Assim, na primeira parte deste trabalho é discutido o problema conceitual, demonstrando-se a grande divergência que há na doutrina sobre a definição de ratio decidendi; no tópico seguinte, é examinado o desenvolvimento do conceito na doutrina estrangeira e, na sequencia, a proposta nacional de adesão ao elemento determinante - eleito pelo legislador ordinário - como integrante do conceito de ratio, para, por fim, apresentar a norma de julgamento como a soma dos elementos fático materiais, 
solução jurídica e motivação justificatória ${ }^{1}$, que se pretende demonstrar imprescindível à renovação do direito jurisdicional ao passo das evoluções sociais, pela garantia de participação no processo decisório.

Antes, porém, ainda à título de introdução, deve-se estabelecer a premissa de que não é toda decisão judicial - não importa se de um único julgador ou se de um órgão colegiado, tampouco se proferida por um juiz de primeira instância ou se de Corte Suprema - que tem pretensão (ou aptidão) para constituir um precedente.

É bem verdade que as exigências de coerência, estabilidade e integridade que a ordem social reclama de qualquer sistema jurídico com pretensão de justiça imponha a cada julgador ou órgão colegiado o dever de consistência em suas posições, a garantir que a mesma solução jurídica seja apresentada para casos análogos. Ocorre que essas soluções não vinculam outros julgadores senão quando definidas por órgãos de superior hierarquia institucional. Daí porque se diz que precedentes é uma metodologia para Cortes Superiores ou Cortes Supremas (ZANETI JUNIOR, 2019, p. 311).

Portanto, sob o ponto de vista de sua formação, os precedentes são soluções jurídicas apresentadas por órgãos colegiados aos conflitos deduzidos em uma ação concreta. Mas há ainda um outro dado essencial a ser considerado antes de prosseguir com o exame dos elementos constitutivos do precedente e cujo conhecimento é imprescindível para a correta compreensão da teoria, qual seja, a adição de glosas ao texto legal como etapa necessária para a adjudicação do conflito. Isso porque, se a solução da controvérsia for dirimida pela aplicação da lei ao caso concreto, a vinculação, nesse caso, advém da própria lei, de modo que, no julgamento de um caso análogo, qualquer juiz ou tribunal deverá alcançar a mesma solução porque definida em lei - e não no precedente.

Por outro lado, havendo o controle sobre a interpretação da lei ou a densificação dos sentidos possíveis à luz de um caso objetivo, com a adição de glosas ao texto, a solução alcançada a

\footnotetext{
${ }^{1}$ A escolha do termo motivação, à fundamentação, tem a ver com a admissão de que os juízos (percepções da realidade posta) são sempre parciais. Enquanto o fundamento tem a pretensão de ser "a essência posta como totalidade" (ABBAGNANO, 2020, p. 553), o motivo, é "a causa ou condição de uma escolha, ou seja, de uma volição ou de uma ação" (ABBAGNANO, 2020, p. 797), o que corresponde a uma visão muito mais realista da atividade judicial. Isso não siginifa, porém, que a escolha do julgador seja discricionária, antes, para ser legítima, precisa atender aos requisitos de justificação interna e externa expostos no tópico 3 deste trabalho.
} 
partir desse caso deve servir de paradigma para a solução de casos futuros, sob pena de esvaziar o sistema jurídico de qualquer racionalidade.

Evidentemente, há muito mais a se considerar para a correta compreensão da teoria, mas, para os propósitos delimitados neste trabalho, acredita-se que esse breve introito seja capaz de orientar o leitor para o exame dos elementos centrais para a constituição de um precedente judicial.

\section{PROBLEMA CONCEITUAL}

Conceituar a ratio decidendi e o obter dicta é uma pretensão que certamente não será satisfeita neste trabalho, isso em razão da grande controvérsia que há sobre os componentes substanciais desses elementos da decisão, especialmente da ratio decidendi, que é o conceito sobre o qual recaem as principais controvérsias.

O único consenso doutrinário parece gravitar em torno das funções desses elementos, sendo a ratio a parte vinculante da decisão, na medida em que é nela que se identifica o conteúdo normativo do caso-precedente, enquanto o obter dicta não possui função vinculatória, sendo normalmente empregado como reforço argumentativo e o critério para a sua identificação, de um e outro, é a exclusão: o que não é ratio, é dicta.

Pierluigi Chiassoni (2011, p. 115-116) elenca 11 conceitos que a doutrina italiana apresenta para ratio decidendi, demonstrando com isso a ampla divergência na definição desse elemento, alguns tão discordantes que sequer é possível estabelecer uma relação entre eles senão a compreensão geral que classifica a ratio como norma jurídica do caso e, mesmo assim, há quem tenha considerado a ratio como argumentação, como Marino Bin (CHIASSONI, 1999, p. 148), o que sugere um caráter meramente persuasivo do pronunciamento judicial.

É bem verdade que o ordenamento jurídico italiano não adota uma teoria de precedentes, não admitindo valor vinculante obrigatório aos pronunciamentos dos órgãos judiciais na solução jurídica apresentada para um caso concreto, o que, com efeito, pode conduzir à ausência de 
maturação do discurso teórico a respeito do tema, prejudicando qualquer pretensão de maior convergência no conceito dos elementos objetos deste trabalho.

Não obstante, é importante notar que divergências também são verificadas mesmo em países que adotam o sistema jurídico de common law e que, em tese, devido a longevidade de sua cultura de reconstrução do ordenamento jurídico através do direito jurisdicional, poderiam estar mais preparados para apresentar uma conceituação ou uma fórmula de identificação precisa para a ratio decidendi e o obter dictum.

A ausência de consenso acerca do conceito em testilha, para Chiassone, deve-se a "[...] uma combinação condenada a ser um sucesso permanente de esforços de pensamento não muito claro aliado aos comandos da política judiciária, ideologia jurídica e guerrilha metodológica.” (2016, p. 67).

Não saber definir repercute no identificar e, consequentemente, no aplicar, sendo, portanto, um grande problema quando se trata da adoção de uma teoria de precedentes vinculantes.

\section{O DESENVOLVIMENTO DOS CONCEITOS NA DOUTRINA ESTRANGEIRA}

Em 1894, Eugene Wambaugh discorreu que um precedente judicial deveria observar dois princípios: (i) princípio da restrição da jurisdição [aos fatos concreto], já que, segundo o autor, "nenhuma Corte pode decidir a partir de casos imaginários"; e, (ii) princípio da uniformidade, segundo o qual "o tribunal deve decidir cada caso precisamente como faria em caso semelhante, ou seja, de acordo com uma regra geral", de modo que sua decisão possa constituir precedente "[...] para todos os casos em que as circunstâncias não diferem materialmente das circunstâncias em que a decisão foi baseada" (1894, p. 15, tradução nossa).

Como forma de auxiliar na identificação da norma-jurídica do caso precedente, Wambaugh propôs um teste, baseado em uma técnica de inversão que orienta separar o fundamento decisório e nele inserir uma palavra que inverta o seu sentido. Se a inversão for irrelevante para o resultado do julgamento, então o fundamento não constituirá uma ratio, mas um dicta; se, por outro lado, a inversão do sentido resultar na alteração do resultado, então o fundamento constituirá a ratio da decisão. 
Marinoni denuncia a falibilidade desse teste à luz da doutrina contemporânea de common law, pois transforma em dicta os fundamentos que concorrem para a solução do caso em julgamento. Esse teste ignora que a Corte pode eventualmente decidir com base em dois fundamentos que, separadamente, podem levar à mesma solução, e, nesse caso, inverter o significado de qualquer deles não seria suficiente para afastar o resultado, mas isso não quer dizer que a decisão estaria desprovida de ratio (2013, p. 162-163).

Essa concepção de ratio também foi criticada por parecer muito abstrata e generalizante. Assim, em 1930, Arthur Goodhart apresentou uma nova proposta para a sua identificação. Segundo ele, o principle of the case - como ele denomina os fundamentos decisórios deveria ser compreendido à luz dos fatos materiais tal como concebidos pelo julgador do caso-precedente, de modo que "[...] nossa tarefa ao analisar um caso não é declarar os fatos e sua conclusão, mas os fatos materiais como vistos pelo julgador e a conclusão alcançada a partir deles.”, (1930, p. 169, tradução nossa). Sua fórmula, depois de profícuo debate com Alfred Simpson, James Montrose e Julius Stone, foi condensada em artigo publicado em 1959, estabelecendo que a ratio de uma decisão é determinada (i) pelos fatos tratados pelo julgador como materiais, e (ii) por sua decisão baseada naqueles fatos.

Para Thomas Bustamente, o equívoco de Goodhart foi ter dissociado os fatos das regras, já que é a interconexão entre um e outro que direciona a formação do discurso jurídico (2008, p. 109). O autor cita Wrobléski, para quem: "O uso do precedente orientado aos fatos e o uso do precedente orientado às regras são interconexos, porque as regras disciplinam sempre um tipo qualquer de fato, e os fatos no discurso jurídico não podem ser compreendidos fora de suas relações com as regras" (2008, p. 110).

Segundo apontou Lücke (1989, p. 40), Goodhart parecia estar impressionado com o que os advogados alemães de seu tempo chamavam de o poder normativo dos fatos. O comentarista chama a atenção para a irremediável constatação de que "[...] quando os fatos concretos de um precedente podem ser usados para qualificar a norma ou princípio anunciado em uma decisão judicial, deve-se perguntar se os 'fatos' não são os blocos de construção mais importantes de uma regra criada judicialmente” (LUCKE, 1989, p.40, tradução nossa).

Para Marinoni, o método de Goodhart aviva o princípio de que casos iguais devem ser tratados da mesma forma - treat like cases alike (2013, p. 164), mas vulnera a pretensão de 
racionalização da teoria de precedentes, dadas as possíveis inconsistências das cortes quanto à identificação adequada dos fatos materiais sobre os quais basearam o seu julgamento.

Ora, sendo o Direito uma ciência artificial vocacionada a regular a conduta social, visando tanto prevenir como remediar conflitos, e sendo esses conflitos adjetivos de fatos, resta evidente que os fatos materiais sobre os quais recaem a atividade jurisdicional não podem ser negligenciados pelo intérprete. No entanto, a ciência jurídica evoluiu e já não se admite uma teoria do Direito meramente descritiva. A norma, nesse sentido, não é uma decisão prévia, simples e acabada (HABERLE, 1997, p. 30), limitada por uma ideologia da subsunção, mas fruto de uma atividade interpretativa vinculada a uma "teoria jurídica integral", que na visão de Bustamante, exerce a dupla função de reconstruir o raciocínio do julgador e, nesse propósito, estabelecer os parâmetros de justificação seguidos no momento do julgamento, e associar os "logros institucionais que o positivismo alcançou a um construtivismo ético necessário para dar objetividade às regras morais (reconhecidas pela tese da conexão) do Direito" (2008, p. 146-147).

Tomando por base a alegoria dos blocos de construção apresentados por Lücke, não é mais possível dizer que os fatos sejam os únicos blocos para a identificação da ratio, posto que relevantes.

E, sensível a isso, em 1977, o professor Rupert Cross apresentou uma nova fórmula para auxiliar na identificação da ratio. Sua proposta adicionou novos blocos aos argumentos dos autores que o precederam, especialmente Goodhart, que é usado como premissa teórica para o desenvolvimento do seu conceito de ratio decidendi (MOTTA, 2016, [e-book, 3.3.3.3]). Marinoni expõe que, para Rubert Cross, nem sempre a ratio decidendi poderia ser extraída da simples referência aos fatos tomados como materiais pela corte e a decisão tomada a partir deles, sendo frequentemente necessário saber qual o motivo que levaram certos fatos a serem qualificadas dessa maneira e qual o contexto normativo considerado no momento dessa escolha (2013, p. 166).

É possível dizer que Cross acrescenta à fórmula de Goodhart uma exigência de racionalidade na relação entre os fatos materiais e a decisão apresentada para o caso, anunciando que a ratio é " [...] qualquer regra de direito expressa ou implicitamente tratada pelo juiz como um passo 
necessário para chegar à conclusão, considerando-se a linha de raciocínio por ele adotada" (apud MOTTA, 2016, e-book, 3.3.3.3).

Ao exigir que os fatos e a decisão sejam justificados à luz da linha de raciocínio adotada pelo julgador, Cross está ensaiando o que em seguida veio a ser trabalhado por Neil MacCromick como exigência de justificação interna.

Ora, a virada epistemológica exige uma prática argumentativa que seja capaz de satisfazer as pretensões de justiça compreendidas tanto do ponto de vista interno da decisão judicial, como do ponto de vista externo, do ordenamento jurídico integral, o que significa dizer que a decisão deve ser justa para o caso e também para outros casos semelhantes.

A partir da compreensão de que as disputas judiciais são formuladas na base de questões fático-jurídicas sustentadas pelo autor e contestadas pelo oponente, Neil MacCormick passou a argumentar que a decisão judicial deverá estabelecer uma norma de julgamento circunscrita às proposições aduzidas pelas partes, mas que seja logicamente universal (ou pelo menos deduzida em termos que sejam razoavelmente universalizáveis) e aberta à justificativas ulteriores sobre suas consequências e sobre sua consistência e coerência em relação ao ordenamento jurídico (2005, p. 152-153).

Com base nessa compreensão, MacCormick define a ratio decidendi como a norma expressa ou implicitamente empregada pelo juiz como suficiente para resolver uma questão de direito colocada em disputa pelos argumentos das partes em um caso, sendo essa norma necessária para a justificação da decisão tomada para o caso - porquanto não satisfeita por uma regra de direito vigente (2005, p. 153).

Nesse ponto, importa resgatar a ideia trabalhada por Hermes Zaneti Junior, no sentido de que o valor vinculante do precedente advém dos acréscimos interpretativos do julgador às regras de direito vigentes, ou à reconstrução das normas jurídicas advindas da necessidade de colmatar lacunas, conferir efetividade aos direitos fundamentais e às garantias constitucionais dotados de força normativa $(2019,330)$. Isso porque, é essa necessidade de integração do ordenamento jurídico, deduzido num caso concreto, que torna a vinculação ao precedente indispensável à pretensão de conferir racionalidade e inteireza ao direito, evitando as distorções mencionadas na introdução deste artigo. 
Se a integração não for necessária, num caso em que o ordenamento já disponha de normas suficientes para a adequada adjudicação do conflito, o argumento jurídico decisório não formaria uma ratio, mas dicta.

Chama-se a atenção para esses adjetivos: necessário e suficiente, porque sobre tais reside parte da divergência conceitual de ratio decidendi, objeto do tópico seguinte.

\section{RATIO DECIDENDI COMO INTEGRAÇÃO SUFICIENTE}

Parte da doutrina utiliza os predicados necessário e suficiente em referência à decisão do caso, indagando, com efeito, se a decisão acerca de uma questão foi suficiente ou necessária para o julgamento do caso concreto.

Quando a corte resolve mais de uma questão, fica a indagação acerca da natureza das razões apresentadas para cada uma delas, especialmente quando, isoladamente, elas puderem ser consideradas suficientes para a solução do caso. Segundo Marinoni, esse é um problema comum ao common law, vez que, nesse sistema, o precedente "reflete a solução do caso e não a solução das questões nele envolvidas", e, nesse caso, não chegam a um acordo sobre "a natureza dos vários fundamentos que, em princípio, seriam capazes de permitir o alcance da idêntica solução" (2013, p. 173-175), havendo uma tendência de se admitir a decisão sobre uma questão como ratio decidendi, e a outra como dicta, ou, em alguns casos como ratio alternativa (alternative holding), sujeita à escolha do juiz do caso-presente.

No entanto, o conceito de ratio decidendi apresentado por Neil MacCormick parece atribuir outro objeto aos ditos predicados. É que ao dizer que a ratio é a norma expressa ou implicitamente empregada pelo juiz como suficiente para resolver a questão de direito colocada em disputa entre as partes no caso concreto, o predicado está efetivamente atrelado ao julgamento do caso, podendo haver tantas rationes quantas forem as questões decididas suficientes para esse julgamento. No entanto, o autor emprega o predicado necessário para se referir à norma em sua relação com a justificação $d a$ decisão tomada para o caso, no contexto de um ordenamento jurídico existente. Essa proposição está subordinada à primeira e são indissociáveis para a conceituação da ratio decidendi. 
Esses predicados, na filosofia, se relacionam à ideia de fundamento, que, por sua vez, é a causa ou a razão de uma um objeto ser de uma maneira e não de outra. Em Aristóteles, "a causa-razão é um conceito ontológico que expressa a necessidade do ser como substância", mas esse sentido foi abrandado com Graças e Leibniz, passando a designar também um "nexo isento de necessidade, mas capaz de possibilitar o entendimento ou a justificação da coisa”, é o princípio da razão suficiente (ABBAGNANO, 2012, p. 553).

Ora, já é assaz conhecido, tanto na teoria do direito, como na da interpretação, que o ordenamento jurídico e o texto que expressa seus significados não são herméticos e que a permeabilidade do texto, livre de uma teoria capaz de conferir racionalidade à função interpretativa, dá lugar à arbitrariedade e ao decisionismo.

O direito, diferente das ciências naturais, deve acompanhar os padrões do desenvolvimento cultural e em uma sociedade líquida, esses padrões não admitem verdades eternas ou valores absolutos. Por isso a necessidade não pode ser o critério de fundamentação causa-razão para uma questão de direito. Uma reinvindicação nesse sentido exigiria do juiz o atributo da onisciência, devido apenas ao divino. Por isso, as soluções jurídicas apresentadas a essas questões carregam em si a pretensão de serem apenas suficientes para o caso, e essa suficiência é determinada à luz dos argumentos suscitados e conhecidos, do contexto histórico e outros fatores contingenciais, de modo que, soluções contrárias, em momentos futuros ou em contextos diversos, não são em si contraditórias.

Mas a necessidade não deve ser descartada, apenas o seu objeto deve ser alterado: da solução do caso para a atividade do juiz na reconstrução do direito vigente.

Num sistema que concilia múltiplas fontes do direito, e, especialmente, no qual a fonte legal concorre com a fonte judicial - a primeira, de atribuição do Poder Legislativo, a outra, de competência do Poder Judiciário; uma de natureza majoratória num sistema de governo democrático, a outra com função de veto constitucional, voltado para promover e assegurar o caráter normativo das garantias fundamentais - (nessa conjuntura) é possível perceber que a razão de ser de um precedente reside na necessidade de integração do ordenamento jurídico à partir de um paradigma constitucional, ou seja, a solução adjudicada, suficiente para o caso, deve ser necessária para colmatar uma lacuna ou para promover ou garantir efetividade a um direito constitucionalmente reconhecido, porque de outro modo não seria possível fazê-lo. 
Isso significa que se a atuação judicial não é necessária - do ponto de vista já assinalado, para colmatar lacunas ou promover a efetividade de um direito ou garantia - então a norma legal o é, e, nessa perspectiva, qualquer acréscimo argumentativo, pelo juiz, assume o caráter de dicta e não tem força vinculante. A vinculação, nesse caso, é devida à lei.

Mas a necessidade, também aqui, possui um aspecto contingencial. Porque admitido o precedente como fonte do direito, a necessidade de integração deve observar a fonteprecedente. Se essa for suficiente para decidir uma questão do caso-presente, ela será a norma aplicada e a vinculação advém dela, da norma-precedente, que deverá ser recuperada quantas vezes a questão fato-jurídica reaparecer, até que ela já não seja mais suficiente para a decisão de um caso.

Nesse ponto, importa assinalar que Chiassoni considera esses termos "necessário" e "suficiente" uma "conversa solta" na teoria dos precedentes, que culmina na indeterminação da identificação da ratio decidendi. Por isso essas expressões não aparecem em nenhum dos três conceitos formulados pelo autor, quer no objetivo, no subjetivo ou no mixado (2016, p. 69). A doutrina nacional, por sua vez, pretende assinalar um outro elemento para a ratio, os chamados fundamentos determinantes.

\section{A CRÍTICA AOS FUNDAMENTOS DETERMINANTES}

A par dos predicados necessário e suficiente - descartados por Chiassoni - na doutrina nacional é possível identificar um outro adjetivo, a saber, determinante.

"Motivos determinantes" foi o nome eleito pelo legislador pátrio para designar a ratio de uma decisão judicial, estabelecendo no artigo $489, \S 1^{\circ}$, inciso V, do CPC (ou no art. $315, \S 2^{\circ}$, inciso $\mathrm{V}$, do $\mathrm{CPP}$ ) que não se considera fundamentada uma decisão judicial que se limite a “[...] a invocar precedente ou enunciado de súmula, sem identificar seus fundamentos determinantes nem demonstrar que o caso sob julgamento se ajusta àqueles fundamentos".

Ocorre que o elemento determinante, na doutrina, tem sido dotado de significado próprio, que confere à ratio um outro sentido do que aquele trabalhado até este ponto. 
Esse incremento de sentido, a partir do uso do adjetivo determinante, foi suscitado por Marinoni pela compreensão de que a tradução jurídica do sistema de precedentes para o direito nacional impunha atribuir à ratio decidendi um outro elemento capaz de facilitar o seu reconhecimento num sistema jurídico que abriga Cortes Supremas.

A função de uma Corte Suprema é atribuir sentido ao direito e, apesar dessa atividade ser exercida no âmbito de uma determinada ação, estimulada pela iniciativa ou o recurso de uma parte, o julgamento proferido por semelhante tribunal não deve ser pensado para a mera solução do caso, de modo que não é a parte dispositiva da decisão que importa, mas "[...] as razões de decidir ou, mais precisamente, as razões determinantes da solução do caso que assumem relevo quando se tem em conta uma decisão que, além de dizer respeito aos litigantes, projeta-se sobre todos e passa a servir de critério para a solução dos casos futuros.” (MARINONI, 2015, 1.2).

Otávio Motta interpreta que a proposta de Marinoni dá um passo adiante na construção de um conceito adequado para ratio decidendi, mas, para manter a metáfora de construção empregada em outra parte neste trabalho, parece que essa proposta retira um bloco da construção apresentada. Isso porque, com base nas ideias do professor paranaense e de Melvin Eisenberg, Motta afirma que "[...] a ratio decidendi pode ser identificada como as razões determinantes de questões jurídicas debatidas no processo, ainda que não sejam suficientes nem necessárias para determinar a decisão.” (2016, 3.3.3.6.1).

Essa concepção, ao retirar os elementos que confinam a definição de ratio decidendi, apresenta o resultado paradoxal de ampliar o seu conceito, atribuindo força normativa ao pronunciamento de Corte Suprema sobre qualquer questão jurídica debatida pelas partes e discutidas pelo tribunal, ainda que o exame dessa questão seja irrelevante para o julgamento do caso.

O adjetivo determinante, para Otávio Motta, é voltado à reconstrução do direito a partir da solução de questões processuais autônomas e dispensáveis para o julgamento do caso. É dizer, é determinante para a tarefa de conferir unidade à interpretação integrativa do ordenamento jurídico nacional, não para o julgamento do caso. 
A concepção do autor está ancorada na teoria do announcement approach, também de Melvin Eisenberg, que considera a rule de um precedente a rule que ele mesmo impõe, desde que "seja uma decisão a respeito de uma questão relevante suscitada em razão da disputa judicial perante a corte" $(2016,3.3 .3 .6 .1)$.

Mas aqui, parece perfeitamente adequada uma crítica que Marinoni apresentou quando abordou o problema, no common law, acerca da admissão de uma decisão com duas rationes. Ele disse, àquela ocasião, que a preocupação dos juristas daquele sistema está orientada pela possibilidade de uma tal concepção "outorgar ao juiz uma latitude de poder que lhe permita indevidamente influir sobre o futuro desenvolvimento do direito" (2013, p. 174).

E não seria justamente isso que poderia ocorrer se à corte for outorgada a possibilidade de formar rationes sobre questões meramente contingenciais para o julgamento do caso? Não se estaria lhe conferindo uma latitude de poder capaz de influir sobre o desenvolvimento do direito?

\section{A RATIO DECIDENDI COMO FATOS MATERIAIS, SOLUÇÃO JURÍDICA E MOTIVAÇÃO JUSTIFICATÓRIA}

Voltemos à concepção de MacCormick, por ser importante para o desenvolvimento deste trabalho. $\mathrm{O}$ autor confere à ratio decidendi uma função imediata ${ }^{2}$ que se traduz no dever de o juiz motivar e justificar a proposição acolhida em sua decisão.

Na teoria da argumentação, a justificação atua como meio de controle. A justificação interna “[...] é o controle lógico-formal do raciocínio judicial partir do conteúdo do próprio ato decisório" (ZANETI JUNIOR, 2019, p. 161). Ou seja, é o exame de congruência da decisão às premissas estabelecidas pelo julgador. A justificação externa, por sua vez, "[...] trata da fundamentação das premissas da decisão, sua base fática e jurídica, as quais dependem do controle da correta argumentação do juízo ou tribunal no momento da decisão", essa fundamentação, portanto, deve observar “[...] o direito em um determinado ordenamento, em

\footnotetext{
${ }^{2}$ A função mediata é aquela que atribui caráter vinculante à ratio decidendi, a transcendência de seus efeitos para além do caso-precedente.
} 
um dado momento histórico, e aos fatos concretos relacionados a causa." (ZANETI JUNIOR, 2019, p. 161).

Dado a artificialidade do direito, a argumentação para a justificação externa que tenha a pretensão de se acomodar a um estado democrático de direito deve operar no campo da dialética - em contraposição à retórica. Daí a função imediata da ratio em impor ao julgador o dever de motivação.

Numa sociedade pluralista, o direito deve ser construído a partir do diálogo de opostos, do qual a decisão judicial assume a posição de síntese orientada à pacificação do conflito, que é, por si, inevitável.

A dialética põe em operação um argumento a favor da legitimidade da construção judicial do direito. Considerando que o saber humano é sempre parcial, as conclusões de justiça também hão de ser parciais, estando sempre circunscritas àquele saber que, por sua vez, é limitado pelos fatos, pelos argumentos das partes e interessados, pelas restrições intelectuais do julgador, pelo momento histórico e outros elementos contingenciais que afetam o grau de cognoscibilidade da Corte.

Por isso a compreensão de que a síntese do julgamento deve ser construída dentro de um processo democrático, aberto aos intérpretes, com pretensão de promoção de um valor jurídico fundamental ao ordenamento em um dado momento histórico e dentro dos fatos concretos relacionados com a causa.

A exigência de justificação externa resgata a "teoria jurídica integral", pelo qual o direito, enquanto sistema artificial, deve ser construído e reconstruído a partir do paradigma constitucional que apresenta valores jurídicos com pretensão de eficácia normativa. Também decorre da constatação, apresentada pela teoria da interpretação, de que interpretar é um processo aberto que conhece possibilidades e alternativas diversas, sendo tanto mais legítimo, quanto mais aberto à sociedade de intérpretes (HABERLE, 1997, p. 30).

Nesse sentido, a motivação justificatória também deve integrar o conceito de ratio, ao lado dos fatos materiais e da norma jurídica orientada para a solução da questão suficiente ao julgamento do caso, e necessária para a integração do direito. Trata-se do elemento transcendente da decisão judicial, responsável por atribuir à ratio decidendi o seu caráter 
vinculante, porque preocupado com a integridade e coerência do próprio ordenamento jurídico.

Essa proposta de motivação justificatória visa encobrir dois componentes bastante caros à teoria do direito, um baseado na pretensão de autoridade, observada a partir da justificação externa para o exercício da jurisdição; e outro, baseado na pretensão de legitimidade, pela abertura do diálogo jurídico à sociedade de intérpretes.

A concepção de legitimidade por abertura da jurisdição à sociedade de intérpretes, no sentido de que a argumentação jurídica na formação do precedente vincula o julgador na medida e no limite dos argumentos considerados no caso-precedente, a partir da formação da síntese do julgamento, impõe que, se no caso-presente a parte for capaz de apresentar um cotejo de todos os argumentos levados em conta na formação do precedente e apresentar um novo argumento, capaz, em tese, de infirmar a conclusão do caso-precedente, o juiz fica autorizado a aplicar a distinção como instrumento de reabertura do debate, evitando que as travas legais obstem a evolução do direito.

Assim, a ratio como julgamento suficiente para o caso e necessária para suprir uma deficiência normativa do ordenamento jurídico, fica circunscrita aos fundamentos deduzidos e efetivamente considerados como síntese da questão. A suficiência está atrelada ao caso em julgamento, enquanto a necessidade, à reconstrução do direito dentro dos limites cognoscíveis no processo em contraditório. A síntese é a própria motivação justificatória.

Com isso, defende-se que argumento não levados ao exame do julgador, mas que sejam robustos e capazes de, em tese, infirmar o resultado do julgamento podem ser suscitados à nível de distinção e autorizar a superação parcial do precedente - parcial porque circunscrito ao caso, mas estável em relação ao julgador, que doravante, por uma questão de congruência de atividade, de imparcialidade e dever de equidade que fundamentam o stare decisis, deverá se orientar por essa mesma solução jurídica.

O modelo proposto, de incluir os fundamentos justificatórios à luz do cotejo dos argumentos considerados na decisão-precedente, busca enfrentar o risco de engessamento do direito jurisprudencial, tão importante para a evolução da justiça por permitir a melhor adaptação do direito aos contínuos avanços sociais, mas tão ameaçado pelos mecanismos de 
contingenciamento numérico que tornam tão difícil a revisão de precedentes por parte das Cortes Supremas ${ }^{3}$. Além disso, acredita-se que o modelo presta homenagem à garantia de independência funcional interna, na medida em que assegura ao julgador o poder de julgar segundo sua consciência quando identifica um argumento forte não considerado no precedente; por outro lado, se não o identifica, subsiste a obrigação de seguir o precedente, mesmo que discordando dele, já que os juízes de instâncias singelas não possuem nem a competência, nem o poder de rever decisões de Corte Suprema, senão por meio do controledemocrático da racionalidade das normas jurídicas vigentes, incluindo, neste ponto, a norma formada em precedente judicial.

\section{CONCLUSÃO}

Este estudo identificou ampla divergência acerca do conceito de ratio decidendi e os elementos que devem compor essa norma de julgamento. A ausência de uniformidade na compreensão desse componente da decisão judicial num sistema jurídico que abriga a vinculação de precedentes pode ser desastrosa, por isso a necessidade de identificar os seus elementos e funções na determinação da norma jurídica reconstruída judicialmente.

Mostrou-se a evolução do processo doutrinário de conceituação da ratio e os elementos que foram sendo integrados a esse componente da decisão judicial como relevantes para a definição da norma de julgamento. Ao passo em que se buscou demonstrar que as disputas acerca dos predicados necessário e suficiente não são desprovidas de sentido, mas caminham no sentido de sinalizar a parcialidade do direito jurisprudencial. Por isso, afirmou-se que a necessidade não pode ser o critério de fundamentação causa-razão para uma questão de direito, porque sendo o direito uma ciência artificial, não é possível estabelecer uma única resposta certa, extraída ontologicamente. A necessidade, neste caso, tem a ver com a identificação de lacunas que atentam contra a pretensão de organicidade do ordenamento jurídico. As soluções jurídicas, por sua vez, carregam consigo a pretensão de serem apenas suficientes para o caso, e essa suficiência é determinada à luz dos argumentos suscitados e

\footnotetext{
${ }^{3}$ Cite-se, nesse caso, os mecanismos de sobrestamento, retratação e declaração de prejudicialidade dos recursos contra decisões que não destoam do precedente de Cortes Supremas.
} 
conhecidos, do contexto histórico e outros fatores contingenciais, de modo que, soluções contrárias, em momentos futuros ou em contextos diversos, não são em si contraditórias.

Em vista desse desenvolvimento, e em atenção ao potencial engessamento do direito jurisprudencial por mecanismos processuais de contenção numérica, foi proposta a inclusão da motivação justificatória como um elemento da ratio, ponderando-se que, se a decisão judicial é a síntese do debate jurídico desenvolvido para o caso, os fundamentos não levados ao exame do julgador do caso-precedente, mas que sejam robustos e capazes de, em tese, infirmar o resultado daquele julgamento, podem ser suscitados à nível de distinção no casopresente e autorizar a superação da norma de julgamento.

Não é o propósito desse breve estudo esgotar a discussão a respeito do tema, mas permitir que as questões ora suscitadas renovem o debate acerca do papel do direito jurisprudencial e das ferramentas que a sociedade civil dispõe para enfrentar eventuais capturas do processo judicial, permitindo-se a contínua - mas racional - revisão do direito pelos intérpretes empíricos da ordem social, numa deferência à sua autonomia e à pretensão democrática de participação no processo decisório.

\section{REFERÊNCIAS}

ABBAGNANO, Nicola. Dicionário de filosofia. 6. ed. São Paulo: Editora Wmf Martins Fontes, 2012. 1210 p. $1^{\text {a }}$ edição brasileira coordenada e revisada por Alfredo Bosi; revisão da tradução e tradução de novos textos Ivone Castilho Benedetti.

BUSTAMANTE, Thomas da Rosa de. Teoria do direito e decisão racional: temas da teoria da argumentação jurídica. Rio de Janeiro: Renovar, 2008.

DINAMARCO, Cândido Rangel. A instrumentalidade do processo. $3^{\text {a }}$ ed., São Paulo: Malheiros Editores Ltda., 1993.

CHIASSONI, Pierluigi. Diritti umani, Sentenze elusive, claudole ineffabili: scritti di realismo militante. Roma: Aracne editrice, 2011.

La giurisprudenza civile: metodi d'interpretazione e tecniche argomentative.

Milano: Giuffrè Editore, 1999.

A filosofia do precedente: reconstrução racional e análise conceitual. Universitas

Jus, Brasília, v. 27, n. 1, p. 63-79, 29 jun. 2016. Semestral. Traduçao de Thiago Pádua. 
GOODHART, Arthur L.. Determining the ratio decidendi of a case. Yale Law Journal, Sheridan, v. , n. 2, p. 161-183, dez. 1930. 8/Ano.

Precedent in English and Continental law. The Law Quaterly Review, n. CXCVII, v. L, n. 5, p. 40-65, jan. 1934.

. The ratio decidendi of a case. The Modern Law Review, n. 2, vol. 22, p. 117-124, mar. 1959. Disponível em https://onlinelibrary.wiley.com/doi/abs/10.1111/j.14682230.1959.tb02164.x, acesso em 5 jan. 2021.

HABERLE, Peter. Hermenêutica constitucional. A sociedade aberta dos intérpretes da constituição: contribuição para a interpretação pluralista e "procedimental" da constituição. Porto Alegre: Sergio Antônio Fabres Editor, 1997, 55 p.

Lücke, H.K., Ratio Decidendi: Adjudicative Rational and Source of Law, Bond Law Review: Vol. 1, n. 1, artigo 2, p. 36-51, 1989. Disponível em https://blr.scholasticahq.com/article/5173-ratio-decidendi-adjudicative-rational-and-source-oflaw, acesso em 5 jan. 2021.

MOTTA, Otávio Verdi. Justificação da decisão judicial. A elaboração da motivação e a formação do precedente. Direção MARINONI, Luis Guilherme. Coord. ARENHART, Sérgio Cruz, MITIDIERO, Daniel. $1^{\text {a }}$ ed. e-book. São Paulo: Tompson Reuters, 2016.

MARINONI, Luiz Guilherme. Precedentes obrigatórios. $3^{\text {a }}$ ed., revista, atualizada e ampliada, São Paulo: Revista dos Tribunais, 2013, p. 219-325.

. Julgamento nas Cortes Supremas. Precedente e decisão do recurso diante do novo CPC. $1^{\mathrm{a}}$ ed. e-book. São Paulo: Tompson Reuters, 2015.

MACCORMICK, Neil. Rethoric and the rule of law. A theory of legal reasoning. New York: Oxford University Press, 2005.

WAMBAUGH, Eugene. The study of cases: A course of instruction in reading and stating reported cases, composing head-notes and briefs, criticising and comparing authorities, and compiling digests. Boston: Little, Brown and company, 1894. Disponível em https://archive.org/details/cu31924024520607, acesso em 05 jan. 2021.

ZANETI JUNIOR, Hermes. O valor vinculante dos precedentes. Teoria dos precedentes normativos formalmente vinculantes. $4^{\mathrm{a}}$ ed., Salvador: Editora JusPodivm, 2019. 